\title{
Metabolic fingerprinting of Melastoma malabathricum L. extracts using high-performance liquid chromatography-diode array detector combined with chemometric data analysis
}

\author{
Dian Mayasari, Yosi Bayu Murti, Sylvia Utami Tunjung Pratiwi, Sudarsono Sudarsono* \\ Department of Pharmaceutical Biology, Faculty of Pharmacy, Universitas Gadjah Mada, Yogyakarta, Indonesia.
}

\section{ARTICLE INFO \\ Received on: 30/04/2021 \\ Accepted on: 26/06/2021 \\ Available online: 05/09/2021}

Key words:

Anti-MRSA, chemometrics,

HCA, HPLC, Melastoma

malabathricum L., PCA.

\begin{abstract}
Melastoma malabathricum L. is an essential herb that has been traditionally used to treat several ailments such as diarrhea, dysentery, wound, and stomachache. This plant is common across tropical Indo-Pacific archipelagos distributed in various geographical locations of Indonesia. In this study, an effective, accurate, and efficient highperformance liquid chromatography (HPLC) coupled to diode array detectors was developed to evaluate the effect of geographical variations on secondary metabolites of M. malabathricum samples through establishing a fingerprint profile, identification of variations of chromatogram peaks, and determination of anti-methicillin-resistant Staphylococcus aureus (MRSA) activity. Fingerprinting analysis of the extracts was analyzed using chemometric tools including unsupervised data analysis: principal component analysis (PCA) and hierarchical cluster analysis (HCA). PCA values were identified as principal component 1 (PC1) and principal component 2 with $41.229 \%$ and 19.208\%, respectively. Anti-MRSA activity of all samples showed significant inhibition against MRSA bacteria. The results indicate the significance of considering geographic distribution during field-collection efforts since they demonstrate regional metabolic variations in secondary metabolites of M. malabathricum L., as illustrated by HPLC and their anti-MRSA activity. The results also confirm the utility of this approach as a comprehensive evaluation of metabolic variations based on their different geographical locations and pharmacological effects.
\end{abstract}

\section{INTRODUCTION}

Melastoma malabathricum L. is an important herb that grows in temperate and moist regions, like Asia and Pacific Islands, Indian Ocean Islands, South and South-East Asia, China, Taiwan, Australia, and the South Pacific Ocean (Joffry et al., 2012). This plant is traditionally used to treat several ailments related to infectious diseases, for example, diarrhea, dysentery, leucorrhoea, hemorrhoids, cuts and wounds, infection during confinement, toothache, stomachache, flatulence, sore legs, and thrush (Begum and Nath, 2000; Bhardwaj and Gakhar, 2005; Joffry et al., 2012). To treat cuts, the leaves of M. malabathricum

*Corresponding Author

Sudarsono Sudarsono, Department of Pharmaceutical Biology, Faculty of Pharmacy, Universitas Gadjah Mada, Yogyakarta, Indonesia.

E-mail: sudarsono@ugm.ac.id are chewed up, pounded, and applied as a paste on wounds or cuts to stop bleeding (Joffry et al., 2012; Zakaria et al., 2006). The young leaves are eaten for healing of diarrhea, while the young premature leaves are consumed twice daily to cure dysentery (Sajem and Gosai, 2006). Leaves are also utilized to treat mouth ulcers, gastric ulcers, scars, pimples, and black spots on skin (Lohézic-Le Dévéhat et al., 2002). Combinations of leaves and other parts of M. malabathricum are also useful to treat ailments, such as leaves and roots are used as a digestive aid and applied to wounds and pox scars to aid the healing process, while the combination of leaves and flowers is used in the treatment of cholera and prolonged fever, as an astringent in leucorrhea and in curing chronic diarrhea (Joffry et al., 2012; Perry and Metzger, 1980; Sharma et al., 2001).

Melastoma malabathricum possesses a myriad of chemicals exhibiting antibacterial (Alwash, 2013; Choudhury et al., 2011; Omar et al., 2012), anti-inflammatory, antioxidant (Susanti et al., 2008), antidiarrheal (Sunilson et al., 2009), 
antiulcer (Balamurugan et al., 2013), antidiabetic (Balamurugan et al., 2014), and hepatoprotective properties (Kamisan et al., 2013). Biological activities of M. malabathricum are closely mediated via a wide range of bioactive chemical constituents such as flavonoids, flavonoid glycosides, terpenoids, steroids, anthocyanins, and tannins (Joffry et al., 2012; Susanti et al., 2008; Wong et al., 2012; Yoshida et al., 1992). A large number of flavonoids and their glycosides, such as quercetin, kaempferol, quercitrin, rutin, and naringin, were isolated from the leaves and flowers of M. malabathricum L. (Susanti et al., 2008; Wong et al., 2012). Additionally, M. malabathricum L. is known to contain several tannins such as malabathrin A, malabathrin B, malabathrin $\mathrm{C}$, malabathrin D, strictinin, casuarinin, pedunculagin, pterocarinin C, nobotanin B, nobotanin D, and nobotanin G (Yoshida et al., 1992).

The metabolites of M. malabathricum leaves could be affected by several factors such as geographical location, altitude, cultivation area, micro- and macronutrients, $\mathrm{pH}$ of soil, climate, harvesting time, and storage method (Ncube et al., 2012). The effect of higher temperature, various precipitation levels, different soil moisture, and fertility might affect the plant's phenology, nutrient, antioxidant, and secondary metabolite levels (Kumar et al., 2017). Chemical constituent variations of plant extracts can be revealed by analytical and chemical techniques including chromatograms, spectrograms, and other graphs (Maimaiti et al., 2020). From these techniques, chemometrics can potentially characterize and identify both the marker components and the unknown components in a complex system (Maimaiti et al., 2020; Toyang and Verpoorte, 2013). Nowadays, assessments of one or two marker compounds or pharmacologically active components in herbal mixtures are currently carried out to assess the quality and authenticity of complex herbal medicines (Feng et al., 2014; Maimaiti et al., 2020).

The application of extraction and analytical methods of all metabolites in the species is challenging due to the complexity of the plant metabolomes (Leme et al., 2014). With the development of analytical techniques, chromatographic fingerprints have been widely used for the authenticity tests or to provide quality control of herbal medicines (Feng et al., 2014; Gan and Ye, 2006). In the past several years, chromatographic fingerprinting or discriminating analysis has been established using high-performance thin layer chromatography, fourier transform infra-red, and ultra performance liquid chromatography (Aziemin et al., 2014; Gu et al., 2017).
High-performance liquid chromatography (HPLC) is one of the most popular methods that is widely used due to its convenience and efficiency (Duan et al., 2012). To the best of our knowledge, there are no previous reports on the development of a fingerprint study of the M. malabathricum herbal profiles to distinguish their geographical locations in archipelago and terrestrial regions. This study will be the first one.

In this study, a simple, sensitive, and reliable HPLC coupled to diode array detector (DAD) methods was employed for establishing the metabolomic fingerprints of 72 samples of M. malabathricum leaves from various geographical locations and assessment for anti-methicillin-resistant Staphylococcus aureus (anti-MRSA) activity. Combined with chemometric tools, including principal component analysis (PCA) and hierarchical cluster analysis (HCA), a method and pattern recognition technique for quality control of $M$. malabathricum could provide the reference for quality control of traditional medicinal plants such as M. malabathricum.

\section{MATERIALS AND METHODS}

\section{Collection of plant material}

Specimens of $M$. malabathricum leaves (72 samples) were collected during June 2019 from different localities and host sites covering six geographical zones in terrestrial and archipelago places of Indonesia. Each location contained six sampling spots. The leaves were identified by their morphological characteristics and then compared with previously deposited specimens in the Department of Pharmaceutical Biology, Universitas Gadjah Mada, Indonesia.

Fresh and healthy specimens of leaves of $M$. malabathricum were collected from individual plants at each location. Samples were placed in sterile plastic bags and were brought to the laboratory in an icebox for analyses. The specimen's code, location, date of collection, province, and coordinate sites are shown in Table 1.

\section{Chemicals and reagents}

Chromatographic grade acetonitrile and methanol were purchased from Fisher Scientific Corporation (Loughborough, UK). HPLC-grade trifluoroacetic acid (TFA) acid was purchased from Merck (Darmstadt, Germany). Distilled water was obtained from a local purified water provider.

Table 1. Melastoma malabathricum leaves collected from different locations of Sumatra Island, Indonesia.

\begin{tabular}{ccccc}
\hline Code & Location & Date of collection & Province & Coordinate \\
\hline TP & Tanjungpinang & June 2019 & Riau Island & $0^{\circ} 54^{\prime} 20^{\prime \prime} \mathrm{N} 104^{\circ} 28^{\prime} 7^{\prime \prime} \mathrm{E}$ \\
$\mathrm{BN}$ & Bintan & June 2019 & Riau Island & $1^{\circ} 6^{\prime} 12^{\prime \prime} \mathrm{N} 104^{\circ} 23^{\prime} 36^{\prime \prime} \mathrm{E}$ \\
$\mathrm{KR}$ & Karimun & June 2019 & Riau Island & $0^{\circ} 48^{\prime} 50^{\prime \prime} \mathrm{N} 103^{\circ} 30^{\prime} 58^{\prime \prime} \mathrm{E}$ \\
$\mathrm{MR}$ & Meranti & June 2019 & Riau & $1^{\circ} 0^{\prime} 25^{\prime \prime} \mathrm{N} 102^{\circ} 42^{\prime} 36^{\prime \prime} \mathrm{E}$ \\
$\mathrm{KM}$ & Kampar & June 2019 & Riau & $0^{\circ} 26^{\prime} 38^{\prime \prime} \mathrm{N} 101^{\circ} 19^{\prime} 32^{\prime \prime} \mathrm{E}$ \\
$\mathrm{KS}$ & Kuantan Singingi & June2019 & Riau & $0^{\circ} 33^{\prime} 2^{\prime \prime} \mathrm{S} 101^{\circ} 32^{\prime} 11^{\prime \prime} \mathrm{E}$ \\
\hline
\end{tabular}

Collection spots were divided into two provinces. Each province provided six individual plant specimens involving Tanjungpinang (TP 1-6), Bintan (BN 1-6), and Karimun (KR 1-6) districts in Riau Island province and Meranti (MR 1-6), Kampar (KM 1-6), and Kuantan Singingi (KS 1-6) districts in Riau province. 


\section{Preparation of extracts}

Air-dried leaves of M. malabathricum L. samples were ground with a pestle and mortar. The powder (100 mg) was

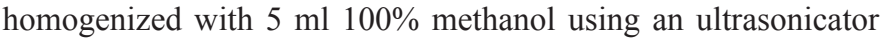
bath $(40 \mathrm{kHz})$ for 30 minutes. After the mixture cooled to room temperature, the extract was filtered through a $0.45 \mu \mathrm{m}$ membrane filter and $20 \mu \mathrm{l}$ injected into the HPLC system analysis.

\section{HPLC conditions}

The HPLC analysis was carried out on a Shimadzu Prominence high-performance liquid chromatography system (Shimadzu Corporation, Kyoto, Japan) equipped with a lowpressure gradient pump, a vacuum degasser, a thermostat column compartment, Photodiode Array (PDA) detector, and HPLC controller connected to the LabSolution data analysis software. The LiChrospher RP $18-5$ column $(15 \mathrm{~cm} \times 3.2 \mathrm{~mm} \times$ particle size of $5 \mu \mathrm{m}$ ) was applied for chromatographic separation. The composition of the gradient mobile phase was water (A), $0.1 \%$ TFA in methanol (B), and acetonitrile $(\mathrm{C})$. The gradient elution program was as follows: (1) $0.0-0.01$ minutes, $65 \% \mathrm{~A}, 30 \% \mathrm{~B}$, and $10 \% \mathrm{C}$, (2) $0.01-3.0$ minutes, $10 \% \mathrm{C}, 60 \% \mathrm{~A}$, and $30 \% \mathrm{~B}$, (3) $3.0-23.0$ minutes, $10 \%-70 \% \mathrm{C}, 60 \%-0 \% \mathrm{~A}$, and $30 \% \mathrm{~B}$, (4) 23.0 25.0 minutes, $30 \% \mathrm{~B}$, and $70 \% \mathrm{C}$, and (5) $25.0-27.0$ minutes. The column temperature was maintained at $30^{\circ} \mathrm{C}$. The flow rate was set at $1 \mathrm{ml} /$ minutes and the injection volume was $20 \mu \mathrm{l}$. The mobile phase was filtered using the Polyvinylidene fluoride (PVDF) filter membrane $0.45 \mu \mathrm{m}$. The ultraviolet (UV) absorbance was monitored at the range of $190-800 \mathrm{~nm}$.

\section{Antimicrobial properties}

The microorganism MRSA (American Type Culture Collection 33591) was used for the determination of the antibacterial activity of M. malabathricum extracts. Microbroth dilution assays were used to determine percent inhibition of the samples against MRSA. The concentrations of the extracts used for antibacterial assay were all $50 \mu \mathrm{g} / \mathrm{ml}$. In brief, $80 \mu \mathrm{l}$ of broth heart infusion media was loaded in sterile flat-bottomed 96-well plates. A volume of $20 \mu \mathrm{l}$ of each plant extract was pipetted onto the plate and mixed using a micropipette. The starting bacterial strain suspension was $1 \times 10^{6} \mathrm{CFU} / \mathrm{ml}$ and the wells containing bacterial inoculum without any extract were served as a control. The inoculated plates were incubated at $37^{\circ} \mathrm{C}$ for $18-24$ hours. The experiments were repeated in triplicate. The growth of bacteria was detected by optical density (OD) at $600 \mathrm{~nm}$ and percentage bacterial growth inhibition was calculated based on the formula given as follows:

Percentage growth inhibition $(\%)=\frac{\begin{array}{c}\text { OD of control }- \text { OD of } \\ \text { sample }\end{array}}{\text { OD of control }}$

\section{Data analysis}

HPLC chromatogram profiles including retention time, area, height, concentration, and percent area were analyzed using Microsoft Excel version 2013. The data were processed by multivariate statistical techniques, namely PCA and HCA. The multivariate data analysis, PCA, and HCA were carried out by PAST3 software (Hammer et al., 2001).

\section{RESULTS AND DISCUSSION}

\section{Optimization of HPLC condition}

After sample preparation, the determination of chromatographic separation conditions was the significant steps in the plant extract analysis. The analysis was nontargeted analysis; therefore, the main purpose was to obtain a satisfactory separation of all substances contained in tested samples. The untargeted metabolomics would represent the analytical approach for an accurate evaluation of the qualitative changes in bioactive substances. First, an HPLC-DAD metabolic fingerprinting method was optimized in order to detect as many metabolites as possible by varied different factors to increase the number of compounds separated (Alaerts et al., 2007). Various HPLC parameters including the mobile phase (methanol, water, and acetonitrile), detection wavelength $(190,245,312$, and $360 \mathrm{~nm})$, and flow rate $(1 \mathrm{ml} /$ minute and $0.5 \mathrm{ml} /$ minutes $)$ were optimized to obtain separation efficiency and good shaped peaks of the chromatogram profiles. A good peak shape, chromatographic resolution, and retention time stability are vital for rapid data mining procedures and alignment within metabolomic analyses (Rubert et al., 2015).

After several different HPLC parameters were tried, a set of optimum HPLC parameters was reached, which consisted of a detection wavelength of $312 \mathrm{~nm}$. This wavelength was chosen after comparing separated peaks and their profiles chromatograms with the number of wavelengths. The selected flow rate was $1 \mathrm{ml} /$ minute that provided the best peak resolution. For the mobile phase, first water and $0.1 \%$ TFA in methanol were mixed with a composition of 70:30, and then to obtain the best separation, acetonitrile was added to the mixture solvents. By taking several combinations and compositions of mobile phase into consideration, water : methanol 0.1\% TFA (90:10 and 70:30), water : methanol $0.1 \%$ TFA:acetonitrile (60:30:10), and water: methanol $0.1 \%$ TFA : acetonitrile $(65: 30: 5)$, it was found that $0.1 \%$ TFA in the methanol-water-acetonitrile system gave better resolution and better peak shapes than other systems. TFA $(0.1 \%$ $v / v$ ) was applied as an additive in the methanol, which could facilitate a better solution by reducing peak tailing (Chen et al., 2015). TFA is often used in laboratories to control the peak shape of basic compounds by ensuring that residual silanols ubiquitous in the silica-based C18 columns are in their neutral charge state (McClain and Streckfuss, 2014). The column temperature was set at $30^{\circ} \mathrm{C}$.

\section{HPLC fingerprints of extract samples}

This study aimed to investigate $M$. malabathricum secondary metabolites in an untargeted analysis of their genetic diversity based on differences of geographical origin so as to set a framework of pattern-based secondary metabolites or potential uses determination. To accomplish the purpose, methanol extraction combined with HPLC-DAD was utilized for metabolic fingerprinting analysis of 72 samples of M. malabathricum collected from different locations including archipelago and terrestrial regions in Indonesia. Based on fingerprint analysis, the common peak is found present in each extract sample and these peaks should be well separated and have large areas. Extracts were analyzed in a range of UV wavelength of 190-800 $\mathrm{nm}$. Metabolite assignments were based on retention time and peak 
area, with approximately 45 peaks found in each individual sample. Peaks that existed in all samples with good resolution and reasonable heights were assigned as common peaks to express the characteristics of $M$. malabathricum chromatogram extracts. The HPLC-DAD qualitative analyses of the representative fingerprint profiles of samples are shown in Figure 1.

Based on Figure 1, there were eight common peaks found in all samples from different geographical locations at retention time: $15.30,15.60,21.50,22.09,22.55,24.40,24.70$, and 24.997 minutes. These retention times were found in each area but were different in the intensity of the peak. Sample A [Tanjungpinang (TP)] encompassed a significantly more intense peak with 12 major peaks. Peaks 2, 3, and 4 were likely to be clear compared to the other samples. The prominent peaks for sample A regarding the retention times were observed at 3.895.81, 10.72-13.23, 20.49-22.54, and 24.11-26.76 minutes. Overall, there was a need to conduct further investigation through more sophisticated methods to identify which metabolites were represented by the aforementioned HPLC data. Sample B [Bintan (BN)] was dominated by peaks $1,2,5,6,8,9,10,11$, and 12 , whereas peak 7 constituted a major peak in samples A and C. Peak 8 was predominately shown in samples $\mathrm{B}, \mathrm{D}, \mathrm{E}$, and F, and these are the samples from the terrestrial region. The peaks that were site-specific were 1, 2, 3, and 4 due to their presence in samples from only several regions, whereas the common peaks were found in peaks 5-8 and 9-12 due to their presence in specimens from all regions.

Peak number 5 (Rt: 15.30 minutes) was chosen as a maximum peak in the middle of the chromatogram. According to the literature, based on retention time and chromatographic profile, peak numbers 1 and 2 (Rt: 5.1 and 8.1 minutes) are likely to be flavonoid glycoside compounds: isoquercitrin and quercitrin, respectively. Metabolites were eluted in a decreasing order of polarity, where the compounds with high polarity appeared first in the chromatogram, followed by low polarity and nonpolar compounds. Differences and similarities among the samples of $M$. malabathricum extracts were apparent by visual investigations of the HPLC chromatograms.

\section{Principal component analysis (PCA)}

PCA is one of the powerful tools in chemometrics that involves unsupervised multivariate methods allowing the reduction of the data matrix, evaluation of samples clustering tendency, and outlier detection based solely on data matric (Massart, 1997). In PCA, no prior knowledge is required for the classification of the samples or to which specific group they belong. In this study, PCA was employed as a holistic approach to analyze HPLC data sets and to explore relative variability within the different extracts based on their geographical variations. It has been reported that PCA is an efficient tool, whereby several principal components (PCs) were extracted to verify the most possible variability based on the multivariate variation data. From 72 samples, peak chromatogram signals extracted from HPLC-DAD were used for PCA modeling. PCA score plots indicated a visual variation among groups. A macroscopic classification appeared in the score plot of the first two PCs, with which samples could be discriminated according to different regions. The model prescribed by principal component 1 (PC1) accounted for $41.229 \%$ of the variance, whereas principal component 2 (PC2) explained 19.208\%. This classification is shown in Figure 2.

In the score plot, four PCs accounting for $76.94 \%$ of the total variance were considered significant. From the scatter points, the samples could be classified into three obvious main groups [Cluster I: TP and BN districts; Cluster II: Kuantan Singingi (KS), Meranti (MR), and Karimun (KR) districts; Cluster III: Kampar (KM) district], which were distinguished as groups depending on different. This showed the geographical relationships and distribution patterns among samples in Riau and Riau Archipelago

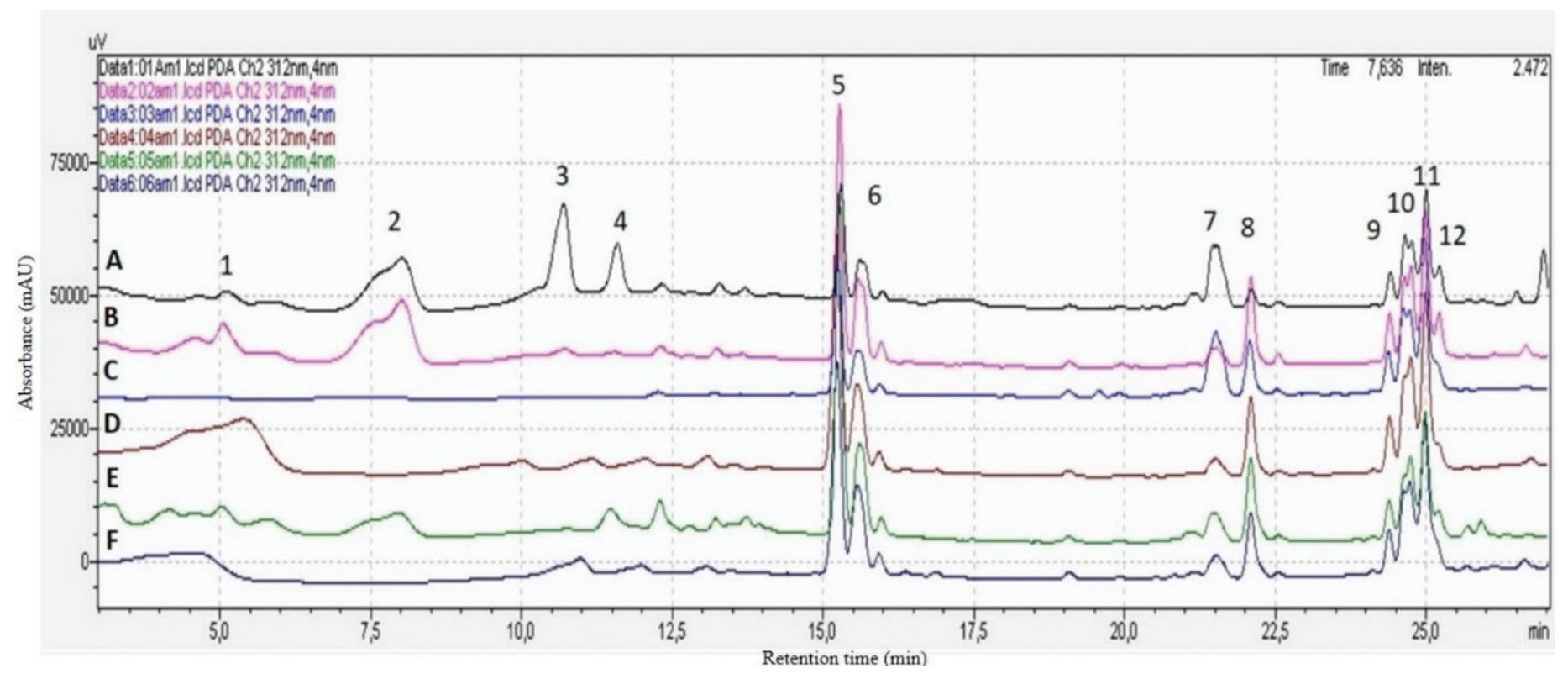

Figure 1. HPLC chromtographic fingerprint peaks of M. malabathricum samples from different regions. The different locations included A(TP), B (BN), and C (KR) from Riau Island province and D (MR), E (KM), and F (KS) from Riau province. Sample from A (TP) has 12 major chromatogram profile peaks as shown previosuly. 


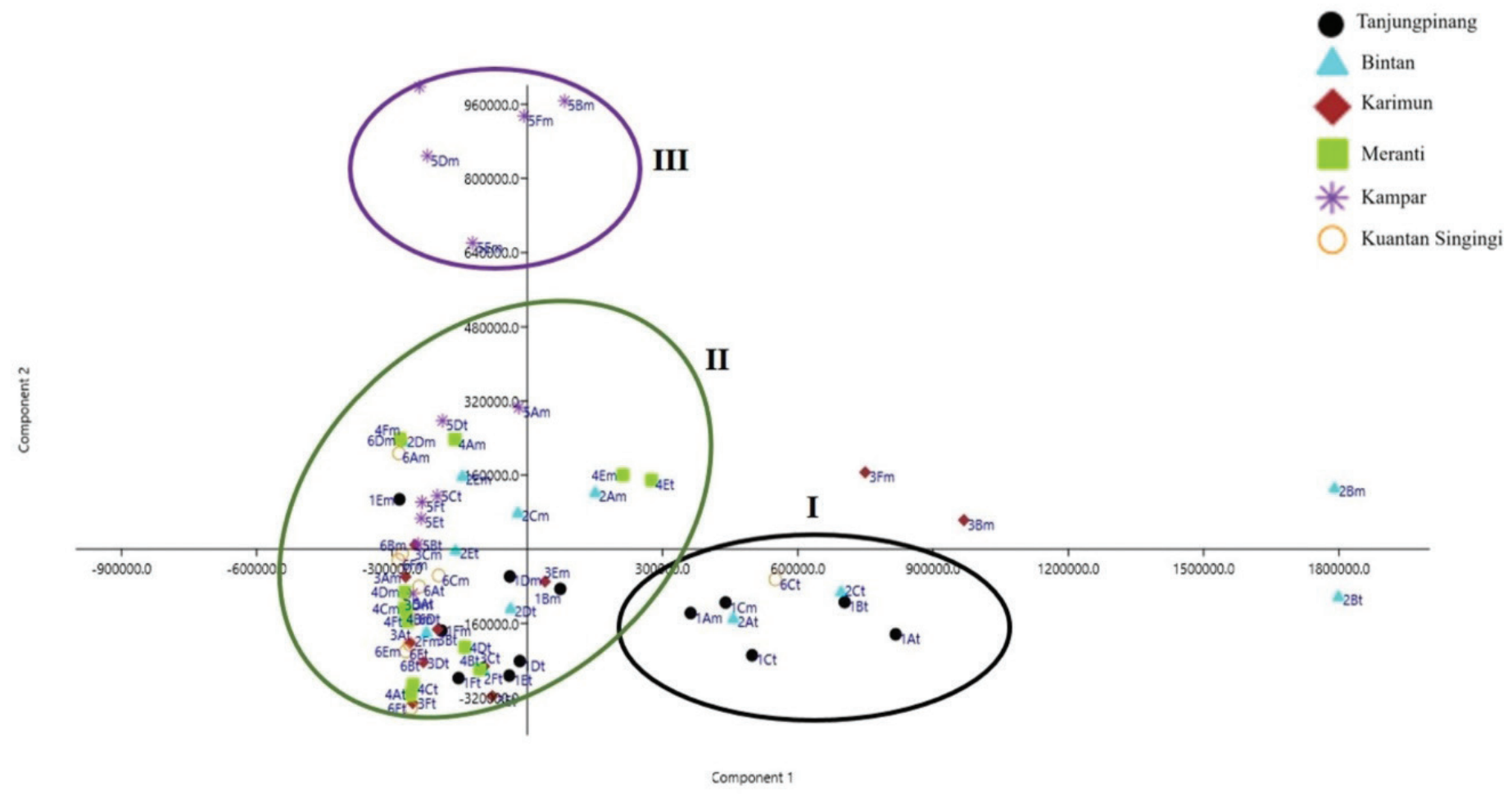

Figure 2. PCA score plot for six regions of the M. malabathricum extract samples. Group 1 included samples from TP and BN; Group 2 samples were from KM; and Group 3 samples were from MR, KR, and KS.

province. It is worth mentioning that $1 \mathrm{em}, 1 \mathrm{bm}, 1 \mathrm{bt}$, and $1 \mathrm{Dt}$ from Cluster I were divided into Cluster II, which demonstrated that a closer geographical relationship was found within the TP district than the KR and MR districts. The sample records from the edges of BN district and KM district also confirmed this point. Moreover, compared with those of TP district, the samples from KM district have a larger scattered region, which suggested that the samples from KM district had a greater quality variation than those of the TP district. However, a large drift was found in a few samples, which indicated a remarkable difference in composition or content in comparison with other samples. The results indicated that different origins were the main reason for variations of $\mathrm{PC}$ constituents and amount. Moreover, other factors, including climate, soil type, harvesting time, storage condition, and harvesting and processing should also be considered. Geographical differences were very revealing in the results of classification. A simplified form of the data was obtained for the quality assurance of M. malabathricum by evaluating the variations and similarities between the samples. According to Figure 2, on the left side of the plot, specimens for samples KR, MR, and KS were positioned (negative PC1 values), whereas samples TP and BN were segregated on the right side (positive PC1 values). Samples of the M. malabathricum L. extracts were scattered widely along the right- and left-hand sides of the PC2 and showed tight clustering. Sample KM showed up in sites on the PC2 side having positive PC2 values. It should be noted that, within the terrestrial regions (Riau province), separation based on specimen geographical origin could not be observed as clear in PCA analysis. For example, samples grown in different regions in $\mathrm{MR}, \mathrm{KS}$, and $\mathrm{KR}$ were all clustered together in one group.

\section{Loading plot}

PCA interpretation can be obtained from loading analysis. Loading is the correlation between the original variable and the new variable. Loading provides an indication of which original variables are very significant and influential in the formation of new variables. When the loading is high, the old variables are increasingly influencing the formation of new variables (Sharma, 1996).

The most influential samples of the various samples from different regions were identified through the loading plots (Fig. 3). Examination of the loadings plot of PC1 (Fig. 3A) suggested that chromatogram peak profiles of metabolites detected in the respective peaks at retention times $12.30,15.27,15.59,24.73$, 24.97, and 22.09 minutes were associated positively to PC1. Positive association of variables in PCA revealed that all variables have the same influence and weight value. The peaks at retention times $9.22,12.03,18.56,19.38,21.77,23.51,22.94$, and 26.51 minutes were associated as neutral with little or no influence on the $\mathrm{PC} 1$, whereas the peaks at retention times 5.81, 8.01, 10.25, $11.51,10.72,21.09,21.52$, and 24.62 minutes were associated negatively to $\mathrm{PC} 1$.

For loading plot of PC2 (Fig. 3B), the peaks at retention times 4.7, 5.09, 7.58, 8.01, 10.25, 10.72, 11.51, and 15.27 minutes were associated positively to PC2. The peaks at retention times $13.49,16.71,18.16,19.75,21.09,22.94,23.06$, and 23.81 minutes were associated as neutral and did not play any role in explaining the variation on PC2, whereas the profile peaks at retention times $6.21,7.06,22.09,24.36,24.62,24.73$, and 24.97 minutes were associated negatively to PC2. 

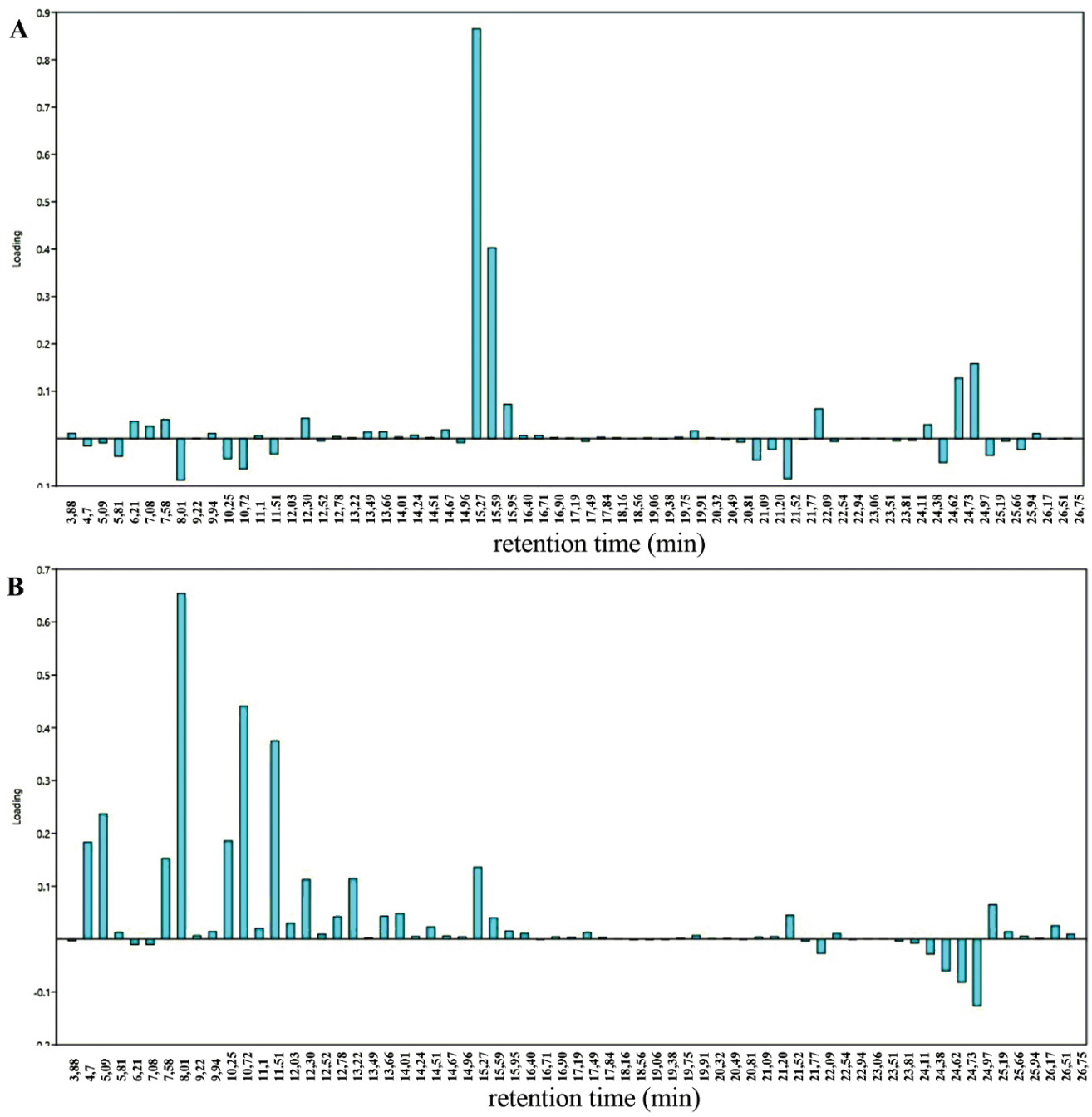

Figure 3. Loading plot of the first two components of the PCA. Loading plot of PC1 (A) and PC2 (B). The $x$-axis represents retention time (minute) of M. malabathricum extracts from different geographical variations and the $y$-axis represents loading.

\section{Hierarchical cluster analysis (HCA)}

HCA was carried out as a continuation of PCA to assess if, by using a different classification algorithm, it is possible to expect more sensitive sample classification, despite their similarity to each other. With regard to PCA, HCA is an unsupervised multivariate method, which evaluates the clustering tendency of samples through an iterative process, which associates the samples by taking account of the chosen distance between samples and a linkage criterion according to which samples or clusters are merged (Bratchell, 1989). In line with PCA, HCA correctly classified the M. malabathricum samples into three clusters according to different geographical variations, as shown in Figure 4.

HCA showed three clusters referred to as groups, which were Clusters I, II, and III. The close clustering of samples from $\mathrm{TP}$ and BN suggested their similarity of metabolite contents in samples involved in Cluster I. The inspection of group II showed that samples from KR, KM, and KS were grouped together, whereas samples from KM were the most distant samples in comparison to others involved in Cluster III. The similarity and group evaluation results showed that location and region differences affected the quality of the extract samples.

\section{Antibacterial activity}

The anti-MRSA activity of the samples from different geographic distributions was measured by the dilution methods. The anti-MRSA activity of all samples is presented in Table 2.

The methanolic extract showed inhibition against test bacteria. Antimicrobial results showed that all extracts were active against MRSA. The present findings indicated that $M$. malabathricum L. may be further explored for the control of infectious diseases. Samples from KR showed the excellent anti-MRSA activity with inhibition activity of $71.63 \% \pm 2.00 \%$, followed by samples from KS, MR, KM, TP, and BN with inhibition of $69.91 \% \pm 4.67 \%, 66.82 \% \pm 4.01 \%, 66.41 \% \pm 3.98 \%$, $59.06 \% \pm 7.69 \%$, and $57.36 \% \pm 3.14 \%$, respectively. This finding was attributed to the PCA and HCA analyses. Samples from KR grouped in one cluster (Cluster III) means that it has a specific 


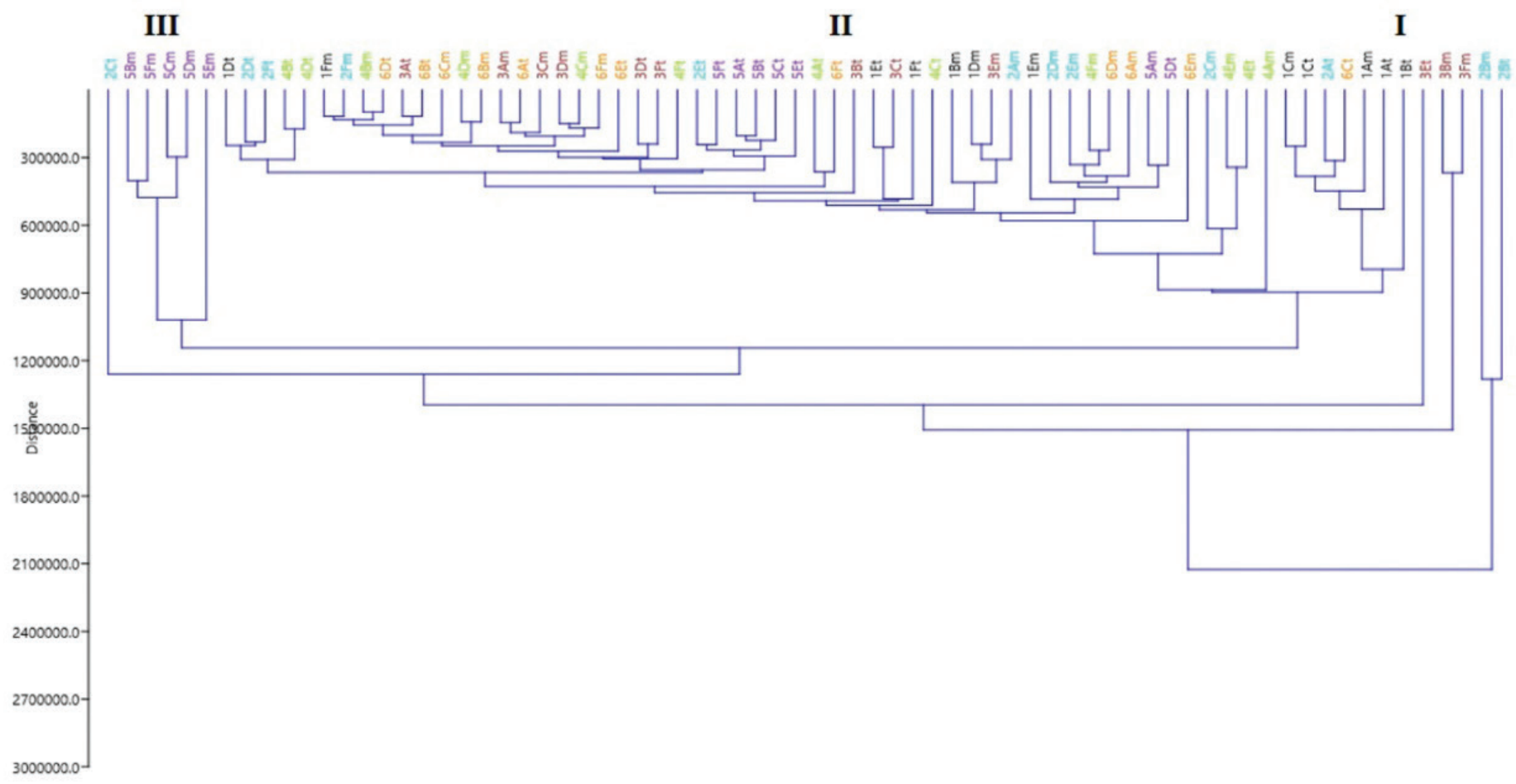

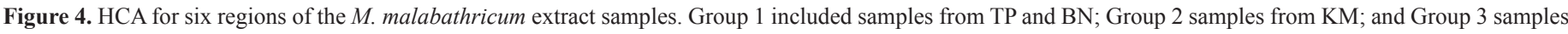
from MR, KR, and $\mathrm{KS}$.

Table 2. Percentage inhibition of M. malabathricum $L$. extract samples from various geographical regions against MRSA.

\begin{tabular}{|c|c|c|c|c|c|}
\hline Samples & Percent inhibition (\%) & Mean \pm SD & Samples & Percent inhibition $(\%)$ & Mean \pm SD \\
\hline $\mathrm{TP}(1)$ & $60.3591 \pm 13.21$ & $59.06 \pm 7.69$ & MR (1) & $64.2265 \pm 2.32$ & $66.82 \pm 4.01$ \\
\hline $\mathrm{TP}(2)$ & $56.7679 \pm 9.73$ & & MR (2) & $65.0552 \pm 3.31$ & \\
\hline $\mathrm{TP}(3)$ & $52.9005 \pm 13.64$ & & MR (3) & $70.1657 \pm 2.92$ & \\
\hline $\mathrm{TP}(4)$ & $56.0773 \pm 4.125$ & & MR (4) & $70.0276 \pm 1.43$ & \\
\hline $\mathrm{TP}(5)$ & $62.4309 \pm 2.40$ & & $\operatorname{MR}(5)$ & $68.0939 \pm 6.81$ & \\
\hline $\mathrm{TP}(6)$ & $65.8839 \pm 3.06$ & & MR (6) & $63.3977 \pm 7.28$ & \\
\hline $\mathrm{BN}(1)$ & $59.9447 \pm 3.60$ & $57.36 \pm 3.14$ & KM (1) & $72.0994 \pm 2.82$ & $66.41 \pm 3.98$ \\
\hline $\mathrm{BN}(2)$ & $36.7403 \pm 2.76$ & & $\mathrm{KM}(2)$ & $66.1602 \pm 3.86$ & \\
\hline $\mathrm{BN}(3)$ & $56.2154 \pm 4.97$ & & KM (3) & $64.6408 \pm 6.20$ & \\
\hline $\mathrm{BN}(4)$ & $69.8895 \pm 2.79$ & & KM (4) & $68.2320 \pm 2.87$ & \\
\hline $\mathrm{BN}(5)$ & $61.1878 \pm 3.61$ & & $\mathrm{KM}(5)$ & $66.0221 \pm 6.17$ & \\
\hline $\mathrm{BN}(6)$ & $60.2209 \pm 1.15$ & & $\mathrm{KM}(6)$ & $61.3259 \pm 1.99$ & \\
\hline $\mathrm{KR}(1)$ & $74.1712 \pm 1.70$ & $71.63 \pm 2.00$ & KS (1) & $70.8563 \pm 6.05$ & $69.91 \pm 4.67$ \\
\hline $\mathrm{KR}(2)$ & $68.3701 \pm 2.01$ & & $\mathrm{KS}(2)$ & $65.4696 \pm 6.01$ & \\
\hline $\mathrm{KR}(3)$ & $76.2430 \pm 0.31$ & & KS (3) & $68.0939 \pm 0.87$ & \\
\hline $\mathrm{KR}(4)$ & $73.3425 \pm 1.74$ & & KS (4) & $69.0607 \pm 5.42$ & \\
\hline $\mathrm{KR}(5)$ & $66.1602 \pm 4.21$ & & KS (5) & $73.8950 \pm 3.72$ & \\
\hline $\operatorname{KR}(6)$ & $71.5469 \pm 2.08$ & & KS (6) & $71.1326 \pm 5.98$ & \\
\hline
\end{tabular}

Each location provided six individual plant specimens such as Riau Island province: Tanjungpinang (TP 1-6); Bintan (BN 1-6); Karimun (KR 1-6) and Riau province: Meranti (MR 1-6); Kampar (KR 1-6); and Kuantan Singingi (KS 1-6).

compound that was different from the others. It had excellent anti-MRSA activity compared to the others that were grouped and clustered close together.
The antibacterial properties of samples from KR were superior to the inhibition of resistant bacteria. All samples showed good inhibition as anti-MRSA activity with a percent 
inhibition of more than $50 \%$. The secondary metabolite contents of M. malabathricum L. leaves were dominated by phenolic compounds such as flavonoids, phenolic acid, and tannins, so the activity against resistant bacteria might be due to the contribution of these phenolics. The mechanisms of antibacterial action of phenolic compounds are known to involve many sites of action at the cellular level by modification in permeability of cell membranes, the changes in various intracellular functions induced by hydrogen bonding of the phenolic compounds to enzymes, or the modification of cell wall rigidity (BouarabChibane et al., 2019).

\section{Geographical variation factor analysis and effect on phytochemical composition}

The PCA was used to analyze the differences in the geographical location of samples in the archipelago and terrestrial regions in Indonesia. The score plot shows that ecological factors of $\mathrm{TP}$ and $\mathrm{BN}$ in the archipelago regions were clustered into one group, and those in KS and MR into another group. TP and $\mathrm{BN}$ are the regions in the archipelago area with an altitude less than 100 meters above sea level (masl), whereas KS and MR involve terrestrial regions with altitude more than 100-500 masl. However, the KM district belongs to the terrestrial area but it is grouped into one cluster. This difference between geographic variations of growth tremendously affects the phytochemical composition of the herbs. These clustering and grouping by chemometric tools are in line with anti-MRSA properties. The KM district which belongs to the terrestrial area has the highest antiMRSA activity. According to Rieger et al. (2008), the production of phenolic compounds provided a significant correlation with altitudes, with increasing altitude followed by increasing the phenolic contents. This finding was also in line with studies by Alonso-Amelot et al. (2007) who found higher amounts of radical scavenging phenolics in higher altitudes sites. Meanwhile, Carey and Wink (2019) found that lower elevation samples contained higher amounts of quinolizidine alkaloids. In this study, the higher altitude (KM district) in the terrestrial regions has higher anti-MRSA activity than that of lower altitude in the archipelago regions. This finding is significantly correlated with previous studies. The phytochemical variation could also be affected by other environmental factors including saline environment, type of soil, micronutrients, and macronutrients. The presence of phenolic compounds has generally contributed to the antimicrobial activity. Polyphenols are well documented to have antimicrobial activity against a number of pathogenic bacteria (Abas et al., 2018; Karou et al., 2005).

\section{CONCLUSION}

Chromatographic fingerprint analysis has become an effective and comprehensive evaluation method for quality control of plant extracts and for species differentiation. The chromatogram profile with peak characteristic fingerprint peaks was selected to evaluate the secondary metabolites among 72 batches of $M$. malabathricum by chemometric tools including PCA and HCA. The results clearly demonstrated that the analytical methods of HPLC-DAD provide valuable qualitative information for the quality assessment of M. malabathricum. The PCA indicated good differentiation of samples of the variation of clusters based on PCs. The PCA analysis was grouped into three clusters. At the same time, we tested the crude plant extracts' anti-MRSA activity. These results revealed that all the extract samples were different based on their geographical location and the anti-MRSA activity depended on the secondary metabolites of the plants. These results demonstrated that the combination of HPLC chromatographic fingerprinting and chemometrics offers an efficient and reliable approach for quality evaluation of $M$. malabathricum extracts based on their geographical variation.

\section{ACKNOWLEDGMENTS}

The authors would like to acknowledge the Faculty of Pharmacy, Universitas Gadjah Mada, Indonesia, for providing the facilities. This work was funded by the Ministry of Research, Technology and Higher Education of the Republic of Indonesia (DIKTI), through the scholarship of Program Magister menuju Doktor untuk sarjana Unggul (PMDSU) with grant No. 2176/UNI. DITLIT/DIT-LIT/PT/2020.

\section{AUTHORS' CONTRIBUTIONS}

Dian Mayasari conducted the research and wrote the original manuscript; Yosi Bayu Murti designed the experiment and helped analyze the data; Sudarsono and Sylvia Utami Tunjung Pratiwi contributed to reviewing and editing the article.

\section{CONFLICT OF INTEREST}

The authors declare that there is no conflict of interests regarding the publication of this paper.

\section{FUNDING}

None.

\section{REFERENCES}

Abas FZ, Zakaria ZA, Ani FN. Antimicrobial properties of optimized microwave-assisted pyroligneous acid from oil palm fiber. J Appl Pharm Sci, 2018; 8:65-71.

Alaerts G, Matthijs N, Smeyers-Verbeke J, Vander HY. Chromatographic fingerprint development for herbal extracts: a screening and optimization methodology on monolithic columns. J Chromatogr A, 2007; 1172(1):1-8.

Alonso-Amelot ME, Oliveros-Bastidas A, Calcagno-Pisarelli MP. Phenolics and condensed tannins of high altitude Pteridium arachnoideum in relation to sunlight exposure, elevation, and rain regime. Biochem Syst Ecol, 2007; 35(1):1-10.

Alwash. Identification and mode of action of antibacterial components from Melastoma malabathricum Linn. leaves. Am J Infect Dis, 2013; 9(2):46-58.

Aziemin A, Dharmaraj S, Hamdan, MR, Mat N, Ismail Z, Mohd KS. Discriminating Ficus deltoidea var. Bornensis from different localities by HPTLC and FTIR fingerprinting. J Appl Pharm Sci, 2014; 4(11):69-75.

Balamurugan K, Nishanthini A, Mohan VR. Antidiabetic and antihyperlipidaemic activity of ethanol extract of Melastoma malabathricum Linn. leaf in alloxan induced diabetic rats. Asian Pac J Trop Biomed, 2014; 4:S442-8.

Balamurugan K, Nishanthini A, Mohan VR. Antiulcer activity of Melastoma malabathricum L. leaf extracts (Melastomataceae). Int J Adv Res, 2013; 1(5):49-52.

Bandet T, Whitehead S, Blondel-Hill E, Wagner K, Cheeptham N. Susceptibility of clinical Moraxella catarrhalis isolates in British Columbia to six empirically prescribed antibiotic agents. Can J Infect Dis Med Microbiol, 2014; 25(3):155-8.

Begum D, Nath SC. Ethnobotanical review of medicinal plants used for skin diseases and related problems in Northeastern India. J Herbs Spices Med Plants, 2000; 7(3):55-93. 
Bhardwaj S, Gakhar SK. Ethnomedicinal plants used by the tribals of Mizoram to cure cuts and wounds. Indian J Tradit Know, 2005; 4(1):1-6.

Bouarab-Chibane L, Forquet V, Lantéri, P, Clément Y, LéonardAkkari L, Oulahal N, Degraeve P, Bordes C. Antibacterial properties of polyphenols: characterization and QSAR (Quantitative Structure-Activity Relationship) models. Front Microbiol, 2019; 10:829. 6(2):105-25.

Bratchell N. Cluster analysis. Chemom Intell Lab Syst, 1989;

Carey DB, Wink M. Elevational variation of quinolizidine alkaloid contents in a lupine (Lupinus argenteus) of the rocky mountains. J Chem Ecol, 2019; 20(4):849-57.

Chen $\mathrm{Y}, \mathrm{Yu} \mathrm{H}, \mathrm{Wu} \mathrm{H}$, Pan Y, Wang K, Jin Y, Zhang C. Characterization and quantification by LC-MS/MS of the chemical components of the heating products of the flavonoids extract in pollen typhae for transformation rule exploration. Molecules, 2015; 20(10):18352-66.

Choudhury MD, Nath D, Talukdar AD. Antimicrobial activity of Melastoma malabathricum L. Assam Univ J Sci Tech, 2011; 7(1):76-8.

Duan B, Huang L, Chen S. Study on the destructive effect to inherent quality of Fritillaria thunbergii Miq. (Zhebeimu) by sulfurfumigated process using chromatographic fingerprinting analysis. Phytomedicine, 2012; 19(6):562-8.

Feng X, Kong W, Wei J, Ou-Yang Z, Yang M. HPLC fingerprint analysis combined with chemometrics for pattern recognition of ginger. Pharm Biol, 2014; 52(3):362-7.

Gan F, Ye R. New approach on similarity analysis of chromatographic fingerprint of herbal medicine. J Chromatogr A, 2006; 1104(1-2):100-5.

Gu C, Zhang X, Wu L, Jiang X, Huang L. Quality evaluation of Dendrobium based on ultra-performance liquid chromatography (UPLC) and chemometrics. J Appl Pharm Sci, 2017; 7(1):017-023.

Hammer O, Harper DAT, Ryan PD. PAST: paleontological statistics software package for education and data analysis. Palaenontol Electron, 2001; 4(1): 10 .

Joffry SM, Yob NJ, Rofiee MS, Mohd Affandi MMRM, Suhaili Z, Othman F, Akim AMd, Desa MNM, Zakaria ZA. Melastoma malabathricum (L.) Smith ethnomedicinal uses, chemical constituents, and pharmacological properties: a review. Evid Based Complement Alternat Med, 2012; 2012:1-48.

Kamisan FH, Yahya F, Ismail NA, Din SS, Mamat SS, Zabidi Z, Zainulddin WNW, Mohtarrudin N, Husain H, Ahmad Z, Zakaria ZA. Hepatoprotective activity of methanol extract of Melastoma malabathricum leaf in rats. J Acupunct Meridian Stud, 2013; 6(1):52-5.

Karou D, Dicko MH, Simpore J, Traore AS. Antioxidant and antibacterial activities of polyphenols from ethnomedicinal plants of Burkina Faso. Afr J Biotechnol, 2005; 4(8):823-8.

Kumar S, Yadav A, Yadav M, Yadav JP. Effect of climate change on phytochemical diversity, total phenolic content and in vitro antioxidant activity of Aloe vera (L.) Burm.f. BMC Res Notes, 2017; 10(1):60.

Leme GM, Coutinho ID, Creste S, Hojo O, Carneiro RL, Bolzani VS, Cavalheiro AJ. HPLC-DAD method for metabolic fingerprinting of the phenotyping of sugarcane genotypes. Anal Methods, 2014; 6(19):7781-8.

Lohézic-Le Dévéhat F, Bakhtiar A, Bézivin C, Amoros M, Boustie J. Antiviral and cytotoxic activities of some Indonesian plants. Fitoterapia, 2002; 73(5):400-5.

Maimaiti, Z, Turak, A, Ma QL, Liu G, Aisa HA. Quantitative determination of marker compounds and fingerprint analysis of the seeds of Vernonia anthelmintica. Int J Anal Chem, 2020; 2020:1-12.

Massart D. Handbook of chemometrics and qualimetrics. 1st Edition, Elsevier, Amsterdam, Netherlands, Vol 20B, 1997.
McClain R, Streckfuss E. (2014). 9.07 High-throughput purification in support of pharmaceutical discovery. In: Knochel $\mathrm{P}$, Molander GA, Comprehensive organic synthesis II. Elsevier, Amsterdam, Netherlands, pp. 160-180.

Ncube B, Finnie JF, Van Staden J. Quality from the field: the impact of environmental factors as quality determinants in medicinal plants. S Afr J Bot, 2012; 82:11-20.

Omar SNC, Abdullah JO, Khairoji KA, Chin SC, Hamid M. Potentials of Melastoma malabathricum Linn. flower and fruit extracts as antimicrobial infusions. Am J Plant Sci, 2012; 03(08):1127-34.

Perry LM, Metzger J. Medicinal plants of East and Southeas Asia: attributed properties and uses. MIT Press, Cambridge, MA, 1980

Rieger G, Müller M, Guttenberger H, Bucar F. Influence of altitudinal variation on the content of phenolic compounds in wild populations of Calluna vulgaris, Sambucus nigra, and Vaccinium myrtillus. J Agric Food Chem, 2008; 56(19):9080-6.

Rubert J, Zachariasova M, Hajslova J. Advances in highresolution mass spectrometry based on metabolomics studies for food: a review. Food Addit Contam Part A, 2015; 32(10):1685-708.

Sajem AL, Gosai K. Traditional use of medicinal plants by the Jaintia tribes in North Cachar Hills district of Assam, Northeast India. J Ethnobiol Ethnomed, 2006; 2(1):33.

Sharma HK, Chhangte L, Dolui AK. Traditional medicinal plants in Mizoram, India. Fitoterapia, 2001; 72(2):146-61.

Sharma S. Applied multivariate techniques. John Wiley \& Sons Inc, Hoboken, NJ, 1996.

Sunilson J, Anandarajagopal K, Kumari A, Mohan S. Antidiarrhoeal activity of leaves of Melastoma malabathricum Linn. Indian J Pharm Sci, 2019; 71(6):691.

Susanti D, Sirat HM, Ahmad F, Ali RM. Bioactive constituents from the leaves of Melastoma malabathricum L. J Ilmiah Farm, 2008; 5(1):1-8.

Toyang NJ, Verpoorte R. A review of the medicinal potentials of plants of the genus Vernonia (Asteraceae). J Ethnopharmacol, 2013; 146(3):681-723.

Wong KC, Ali HDM, Boey, PL. Chemical constituents and antibacterial activity of Melastoma malabathricum L. Nat Prod Res, 2020; 26(7):609-18.

Yoshida T, Nakata F, Hosotani K, Nitta A, Okudat T. Dimeric hydrolysable tannins from Melastoma malabathricum. Phytochemistry, 1992; 31(8):2829-2833.

Zakaria ZA, Raden Mohd Nor RNS, Kumar H, Ghani AZDF, Sulaiman MR, Devi RG, Mat Jais AM, Somchit MN, Fatimah CA. Antinociceptive, anti-inflammatory and antipyretic properties of Melastoma malabathricum leaves aqueous extract in experimental animals. Can J Physiol Pharmacol, 2006; 84(12):1291-9.

How to cite this article:

Mayasari D, Murti YB, Pratiwi SUT, Sudarsono S. Metabolic fingerprinting of Melastoma malabathricum L. extracts using high-performance liquid chromatography-diode array detector combined with chemometric data analysis. J Appl Pharm Sci, 2021; 11(09):048-056. 